\title{
Prevalence and Medications of Atopic Dermatitis in Germany: Claims Data Analysis
}

\author{
Kristina Hagenström (D) \\ Kristin Sauer' \\ Nicole Mohr (D) \\ Marleen Dettmann (ID) \\ Gerd Glaeske (iD ${ }^{2}$ \\ Jana Petersen $\mathbb{1}^{\prime}$ \\ Claudia Garbe $\mathbb{D}^{\prime}$ \\ Tim Steimle ${ }^{3}$ \\ Matthias Augustin (1D) \\ 'German Center for Health Services \\ Research in Dermatology (CVderm), \\ Institute for Health Services Research in \\ Dermatology and Nursing (IVDP), \\ University Medical Center Hamburg- \\ Eppendorf (UKE), Hamburg, Germany; \\ ${ }^{2}$ Research Center on Inequality and \\ Social Policy, University of Bremen, \\ Bremen, Germany; ${ }^{3}$ Techniker \\ Krankenkasse, Hamburg, Germany
}

Correspondence: Kristina Hagenström German Center for Health Services Research in Dermatology (CVderm), Institute for Health Services Research in Dermatology and Nursing (IVDP), University Medical Center HamburgEppendorf (UKE), Martinistraße 52, Hamburg, 20246, Germany Tel +49 (0) 40741055428 Fax +49 (0) 40741055348

Email k.hagenstroem@uke.de
Background: Information on the prevalence of atopic dermatitis (AD) varies greatly, and so far, only a few studies describe the healthcare of patients with AD in Germany.

Objective: The aim of the study is to describe the prevalence and medications of people with AD in Germany.

Methods: Health insurance data for the year 2019 were examined. Prevalence rates, the severity of disease, comorbidities and pharmaceutical supply were analyzed. Insured persons with $\mathrm{AD}$ were identified with at least one outpatient or inpatient International Classification Code of Diseases (L20).

Results: In 2019, 4.21\% [95\% CI 4.21-4.22\%] of insured persons had AD (3.6 million). Women were affected slightly more frequently than men $(4.74 \%$ [95\% CI 4.73-4.74\%] and $3.64 \%$ [95\% CI 3.64-3.65\%]). Adolescents and children under the age of 15 had the highest prevalence of AD compared to other age groups (9.44\% [95\% CI 9.42-9.46\%]). Majority of the insured persons with AD were affected by a mild to moderate form of the disease. The most common co-morbidity was infections of the skin (RR 5.00 [95\% CI 4.97-5.02\%]). Some patients were treated by a dermatologist, while others by a general practitioner, $39.10 \%$ and $36.74 \%$, respectively. Of the anti-inflammatory drugs, systemic glucocorticosteroids preparations were used most frequently and were most frequently prescribed by the general practitioner. With a total of 42,841 prescriptions $(1.53 \%)$, methotrexate (third-line treatment option) was prescribed more frequently than ciclosporin with 19,628 prescriptions $(0.70 \%)$ or azathioprine with 25,696 prescriptions $(0.92 \%)$. Ciclosporin (first-line treatment option) was prescribed much more frequently by a dermatologist $(44.00 \%$ versus $14.32 \%$ by general practitioner). The biological dupilumab was prescribed 30,801 times $(1,10 \%)$ and was also primarily prescribed by a dermatologist $(66.67 \%)$.

Conclusion: The present results reveal that a specialist treats approximately one-third of the patients with $\mathrm{AD}$ and that there is still a drug undersupply in some cases, especially concerning innovative drugs.

Keywords: epidemiology, frequency of illness, pharmaceutical supply, neurodermatitis, statutory health insurance

\section{Introduction}

Atopic dermatitis (AD) is a chronic or chronically recurring inflammatory skin disease, which is accompanied by chronically dry skin and itching (pruritus). The condition can lead to considerable physical and psychological impairment for individuals and their families. People with AD also face financial burdens, social problems and a reduction in quality of life. ${ }^{1,2}$ In addition to the high personal burden of disease, AD presents with public health burden and economic consequences with both direct and indirect costs (eg, sick days from work). ${ }^{3}$ Evidence 
has supported that the burden on working life is significantly higher for those with $\mathrm{AD}$ than their counterparts. ${ }^{4}$

The prevalence of $\mathrm{AD}$ has sharply increased in industrialized countries in the last three decades, with rates doubling and tripling for some countries. ${ }^{5,6}$ There are inconsistent data on prevalence in the literature, ranging from $5 \%$ to $20 \%$ in children and adolescents and between $1 \%$ and $4 \%$ in adults. ${ }^{7-18}$ Correspondingly, in Germany, up to 2.4 million adults and almost 1.3 million children are affected every year.

Recent patient-level healthcare studies reveal that a large proportion of patients with $\mathrm{AD}$ treated by dermatologists in Germany receive a largely guideline compliant treatment. Despite this and the broad access to topical, systemic drugs and phototherapy for other skin diseases, a relevant part of the German patients still suffers from a high burden of disease and a low quality of life which indicates an insufficient medication. ${ }^{1,19}$ In particular, researchers have posited that this may be due to a lack of innovative drugs for systemic treatment. ${ }^{1}$ However, there are only few studies only including dermatological care and these studies are of limited sample sizes (between 1000 and 2000 in each study). To gain more extensive and longitudinal insights in healthcare for AD in Germany, the current study was conducted based on nationwide claims data from a German statutory health insurance (SHI).

\section{Materials and Methods}

\section{Data Source}

For the present study, data were analyzed from the largest and nationwide operating SHI, the Techniker Krankenkasse (TK), which insured 10.5 million Germans in 2019. About 90\% (73.0 million persons) of the German population are covered by one of the 105 different SHI companies, whereas $10 \%$ are covered by substitutive private health insurance. ${ }^{20}$ The study population consists of all TK-insured people of the respective observation year (2019) who were continuously insured or died in this year. This current study analyzed health insurance claims data which included sociodemographic information (eg, age, sex), type of care setting (eg, outpatient and inpatient), and prescribed medication and treatments. ${ }^{21}$

\section{Case Definition and Severity of the Disease}

We identified insured patients who have $\mathrm{AD}$, based on the following inclusion criteria:
At least one of the outpatient (ambulatory primary care) or inpatient (hospital-based) International Classification of Diseases (ICD-10-GM, 10th Revision, German modification) codes (L20, L20.0, L20.8, or L20.9).

Health insurance claims data did not provide sufficient information to characterize the severity of AD. Severity of $\mathrm{AD}$ was operationalized through surrogate markers such as: a) the need of hospital treatment, b) periods of days off work due to the condition, c) use of systemic drugs approved for moderate to severe atopic dermatitis only. Greater use or need of these indicators corresponded with higher disease severity. In this study, insured people with a moderate to severe form of the disease were identified by at least one of the following additional criteria in the year of observation:

- one inpatient (hospital-based) ICD-10-GM code (main discharge diagnosis) with AD (L20, L20.0, L20.8, or L20.9) or

- one specific prescription of systemic agents (Table 1 - see ATC for moderate to severe) or

- one day of incapacity to work due to AD (L20, L20.0, L20.8, or L20.9).

\section{Comorbidities, Pharmaceutical Supply and Prescriber}

Relevant comorbidities were identified through outpatient ICD-10-GM diagnoses (Table 2). All outpatient drug prescriptions (via Anatomical Therapeutic Chemical (ATC) Classification System) for the treatment of patients with AD were identified (Table 1) and categorized by the prescriber (classification of doctor groups according to KBV (2019): general practitioner (GP) (01/02), dermatologist (21), pediatrician (34-47), internist $(03,23-30,32$ -33)). Individual combinations of drug agents were grouped for analyses.

\section{Standards and Ethics}

The study was conducted according to the national guidelines for the use of administrative databases. ${ }^{23,24}$ Based on these guidelines, no approval of an ethical committee is required.

\section{Statistical Analysis}

The annual prevalence rates are reported as percent values with $95 \%$ confidence intervals (CI). All results were extrapolated by means of direct standardization according to KM 6 statistics (all SHI-insured people in Germany ${ }^{25}$ ) by 
Table I Relevant Drugs in Atopic Dermatitis Care

\begin{tabular}{|c|c|c|c|}
\hline & Group & ATC & $\begin{array}{l}\text { Moderate to } \\
\text { Severe } \\
\text { Form }\end{array}$ \\
\hline Topical & $\begin{array}{l}\text { Antibiotics } \\
\text { Antihistamines } \\
\text { Crisaborol } \\
\text { Cromoglicic acid } \\
\text { Urea } \\
\text { Glucocorticosteroids* } \\
\quad \text { Class I } \\
\text { Class II } \\
\text { Class III } \\
\text { Class IV } \\
\text { Combinations with } \\
\text { antiseptics } \\
\text { Combinations with } \\
\text { antibiotics } \\
\text { Other combinations } \\
\text { Pimecrolimus } \\
\text { Psoralene } \\
\text { Tacrolimus } \\
\text { Tars }\end{array}$ & $\begin{array}{l}\text { D06A } \\
\text { D04AA } \\
\text { DIIAH06 } \\
\text { DIIAH03 } \\
\text { D02AE } \\
\text { D07 } \\
\text { D07AA } \\
\text { D07AB } \\
\text { D07AC } \\
\text { D07AD } \\
\text { D07B } \\
\text { D07C } \\
\text { D07X } \\
\text { DIIAH02 } \\
\text { D05AD } \\
\text { DIIAH0I } \\
\text { D05AA }\end{array}$ & \\
\hline $\begin{array}{l}\text { Systemic, non-anti- } \\
\text { inflammatory }\end{array}$ & $\begin{array}{l}\text { Antibiotics } \\
\text { Antihistamines }\end{array}$ & $\begin{array}{l}\text { J0I } \\
\text { R06A }\end{array}$ & \\
\hline $\begin{array}{l}\text { Systemic, } \\
\text { anti-inflammatory, } \\
\text { biologics }\end{array}$ & Dupilumab & DIIAH05 & $x$ \\
\hline $\begin{array}{l}\text { Systemic, anti-inflammatory, } \\
\text { nonbiologicals }\end{array}$ & $\begin{array}{l}\text { Azathioprine } \\
\text { Ciclosporin } \\
\text { Alitretinoin } \\
\text { Glucocorticosteroids } \\
\text { Methotrexat } \\
\text { Mycophenolic acid } \\
\text { Psoralene }\end{array}$ & $\begin{array}{l}\text { L04AX0I } \\
\text { L04ADOI } \\
\text { DIIAH04 } \\
\text { H02AB } \\
\text { LOIBA0I } \\
\text { L04AX03 } \\
\text { MOICX0I } \\
\text { L04AA06 } \\
\text { D05BA02 }\end{array}$ & $\begin{array}{l}x \\
x \\
x \\
x \\
x \\
x \\
x \\
x \\
x\end{array}$ \\
\hline
\end{tabular}

Notes: *The classes of topical glucocorticosteroids based on the national classification: ${ }^{22}$ Class I = weakly effective, Class II = moderately effective, Class III = strongly effective and Class IV = very strongly effective. In practical use, the potency is not necessarily associated with more frequent adverse effects.

Abbreviation: ATC, Anatomical Therapeutic Chemical Classification System.

age, sex and SHI region to the population of all SHIinsured people of the respective year. Differences between the comorbidities of the respective populations considered (AD vs no $A D$ ) were presented using rate ratios (RR) with the respective $95 \% \mathrm{CI}$. All analyses were performed using the statistical software SAS version 9.4 (SAS Institute Inc., Cary, NC).
Table 2 Relevant Comorbidities/Conditions of Atopic Dermatitis Comorbidity

\begin{tabular}{|l|l|}
\hline & ICD-I O-GM Code \\
\hline Obesity & E66 \\
\hline Pruritus & L29 \\
\hline Allergic rhinitis & J30 \\
\hline Cataract & H25, H26 \\
\hline Uveitis & H44.I \\
\hline Alopecia areata & L63 \\
\hline Ulcerative colitis & K5I \\
\hline Crohn's disease & K50 \\
\hline Periodontitis & K05.2, K05.3, K05.4, K05.5, \\
& K05.6 \\
\hline Vitiligo & L80 \\
\hline Lymphoma & C8I-C85, C88, C90, C96 \\
\hline Herpes virus infection & B00 \\
\hline Infections of the skin & L0I \\
\hline ADHD & F90.0, F90.I, F90.8, F90.9, F98.8 \\
\hline Chronic fatigue syndrome & G93.3 \\
\hline Migraine & G43 \\
\hline Sleep apnea & G47.3 \\
\hline Depression & F32, F33 \\
\hline Disease of the metabolic form & ElI, El3, EI4 \\
\hline
\end{tabular}

Abbreviation: ADHD, attention deficit hyperactivity disorder.

\section{Results}

\section{Baseline Characteristics}

The following analyses are based on an extrapolated insured population of all insured people in the SHI (73.0 million) with approximately 37.9 million women and 35.0 million men.

\section{Prevalence}

The prevalence of $\mathrm{AD}$ in the year 2019 was $4.21 \%$ [95\% CI $4.12-4.22 \%$; 3.6 million]. Women were slightly more affected 
Table 3 Age Standardized Prevalence of Atopic Dermatitis by Five-Year Age Groups (Insured Persons in SHI in 2019; N = 73,007,II4)

\begin{tabular}{|c|c|c|c|c|c|c|c|c|c|}
\hline \multirow[t]{2}{*}{ Age Group } & \multicolumn{3}{|c|}{ Male } & \multicolumn{3}{|c|}{ Female } & \multicolumn{3}{|c|}{ Total } \\
\hline & $\mathbf{n}$ & $\%$ & Cl & $\mathbf{n}$ & $\%$ & Cl & $\mathbf{n}$ & $\%$ & Cl \\
\hline$<15$ years & $47 I, 4 I 0$ & 9.62 & $9.60-9.65$ & 428,653 & 924 & $9.21-9.27$ & 900,062 & 9.44 & $9.42-9.46$ \\
\hline $15-19$ years & 84,536 & 4.77 & $4.74-4.81$ & $104,3 \mid 4$ & 6.29 & $6.25-6.33$ & 188,850 & 5.51 & $5.48-5.53$ \\
\hline $20-24$ years & 65,604 & 3.13 & $3.10-3.15$ & 100,734 & 5.22 & $5.19-5.25$ & 166,338 & 4.13 & $4.11-4.15$ \\
\hline $24-29$ years & 64,905 & 2.76 & $2.74-2.78$ & 102,453 & 4.67 & $4.64-4.69$ & 167,358 & 3.68 & $3.67-3.70$ \\
\hline 30-34 years & 68,066 & 2.68 & $2.66-2.70$ & $|I| 2,4 \mid 6$ & 4.64 & $4.6 I-4.66$ & 180,482 & 3.64 & $3.62-3.65$ \\
\hline $35-39$ years & 60,990 & 2.55 & $2.53-2.57$ & 102,622 & 4.33 & $4.30-4.36$ & 163,612 & 3.44 & $3.42-3.45$ \\
\hline $40-44$ years & 51,597 & 2.40 & $2.38-2.42$ & 94,105 & 4.25 & $4.23-4.28$ & 145,702 & 3.34 & $3.32-3.36$ \\
\hline $45-49$ years & 52,663 & 2.36 & $2.34-2.38$ & 96,584 & 4.09 & $4.07-4.12$ & 149,247 & 3.25 & $3.24-3.27$ \\
\hline $50-54$ years & 67,900 & 2.40 & $2.38-2.42$ & $|26| 8 \mid$, & 4.17 & $4.14-4.19$ & $|94,08|$ & 3.31 & $3.30-3.33$ \\
\hline $55-59$ years & 67,314 & 2.38 & $2.36-2.39$ & 123,169 & 4.01 & $3.99-4.04$ & 190,483 & 3.23 & $3.21-3.24$ \\
\hline $60-64$ years & 54,896 & 2.40 & $2.38-2.42$ & 99,083 & 3.84 & $3.82-3.87$ & 153,979 & 3.16 & $3.15-3.18$ \\
\hline $65-69$ years & 45,509 & 2.40 & $2.37-2.42$ & 82,909 & 3.64 & $3.62-3.67$ & 128,419 & 3.08 & $3.06-3.09$ \\
\hline $70-74$ years & 33,335 & 2.38 & $2.35-2.40$ & 59,664 & 3.38 & $3.36-3.4 \mathrm{I}$ & 92,999 & 2.94 & $2.92-2.96$ \\
\hline $75-79$ years & 37,561 & 2.57 & $2.54-2.59$ & 61,822 & 3.13 & $3.11-3.16$ & 99,383 & 2.89 & $2.87-2.91$ \\
\hline $80-84$ years & 33,328 & 2.73 & $2.70-2.76$ & 57,185 & 3.13 & $3.11-3.16$ & 90,513 & 2.97 & $2.95-2.99$ \\
\hline $85-89$ years & 14,528 & 2.71 & $2.67-2.76$ & 27,126 & 2.78 & $2.75-2.81$ & 41,654 & 2.76 & $2.73-2.78$ \\
\hline$\geq 90$ years & 5,540 & 2.58 & $2.5 \mathrm{I}-2.65$ & 15,393 & 2.51 & $2.47-2.55$ & 20,934 & 2.53 & $2.49-2.56$ \\
\hline Total & $\mathrm{I}, 279,682$ & 3.64 & $3.64-3.65$ & $\mathrm{I}, 794,4 \mid 4$ & 4.74 & $4.73-4.74$ & $3,074,095$ & 4.21 & $4.21-4.22$ \\
\hline
\end{tabular}

than men $(4.74 \%$ [95\% CI $4.73-4.74 \%]$ and $3.64 \%$ [95\% CI $3.64-3.65 \%])$. For those under the age of 15 , sex was more equally distributed, with 9.24\% [95\% CI 9.21-9.27\%] in girls and $9.62 \%$ [95\% CI 9.60-9.65\%] in boys. Prevalence differed by age group; insured people under 15 years of age $(9.44 \%$ [95\% CI 9.42-9.46\%]; 900,062; Table 3) had the highest rates. For 15 to 20 year-olds, the prevalence rate was 5.51\% [95\% CI $5.48-5.53 \%$, and only $2.94 \%$ [95\% CI 2.92-2.96\%] of people between 70 and 75 had an AD diagnosis. From the age of 20 years and older, the prevalence was 3.31\% [95\% CI 3.30 $-3.31 \%$, ie, less than half than among those under 15 years of age.

\section{Severity of Disease}

Approximately $12.70 \%$ of the TK-insured persons with AD were affected by a moderate to severe form of the disease. Among the under 15-year-olds, 11.34\% of the patients with AD were affected by a moderate to severe form of the disease. In the age group of 20-yearolds and older, this proportion was slightly higher with $31.27 \%$ without a clear difference between the sexes (male 12.92\%, female 13.47\%). Among those under 15 years of age, moderate to severe AD appeared in $9.07 \%$ of female, compared to around $13.40 \%$ of male patients.

\section{Comorbidities/Conditions}

Compared with patients without $\mathrm{AD}$, patients with $\mathrm{AD}$ had a higher likelihood of the following comorbidities or conditions: infections of the skin $(\mathrm{RR}=5.0[95 \% \mathrm{CI}=5.0$ $-5.0 \%])$, pruritus $(\mathrm{RR}=2.9[95 \% \mathrm{CI}=2.9-2.9 \%])$, alopecia areata $(\mathrm{RR}=2.8[95 \% \mathrm{CI}=2.8-2.8 \%])$ and allergic rhinitis $(\mathrm{RR}=2.6[95 \% \mathrm{CI}=2.6-2.6 \%])$ (Figure 1$)$.

\section{Medication}

In total, $63.16 \%$ of the insured persons with $\mathrm{AD}$ were treated with topical or systemic drug therapy. Approximately $60 \%$ of the children under the age of 15 years received relevant drug treatment. From the age of over 75 years, more than $70 \%$ of the insured persons with $\mathrm{AD}$ received relevant drug treatment. Women over 20 years old received a prescription drug for their AD more often than men $(66.19 \%$ vs $62.59 \%)$. With 2.3 million prescriptions, they had a higher total prescription volume than men (1.3 million).

About $41.60 \%$ of the insured persons with AD received a topical drug and $41.11 \%$ a systemic drug. Most frequently $(65.88 \%)$, insured people with $\mathrm{AD}$ received topical corticosteroids (class III - classification of topical glucocorticosteroids, Table 1). Tacrolimus ointment was administered to $6.31 \%$ of the participants. The majority of the insured people with $\mathrm{AD}$ got antibiotics (non-anti-inflammatory at 


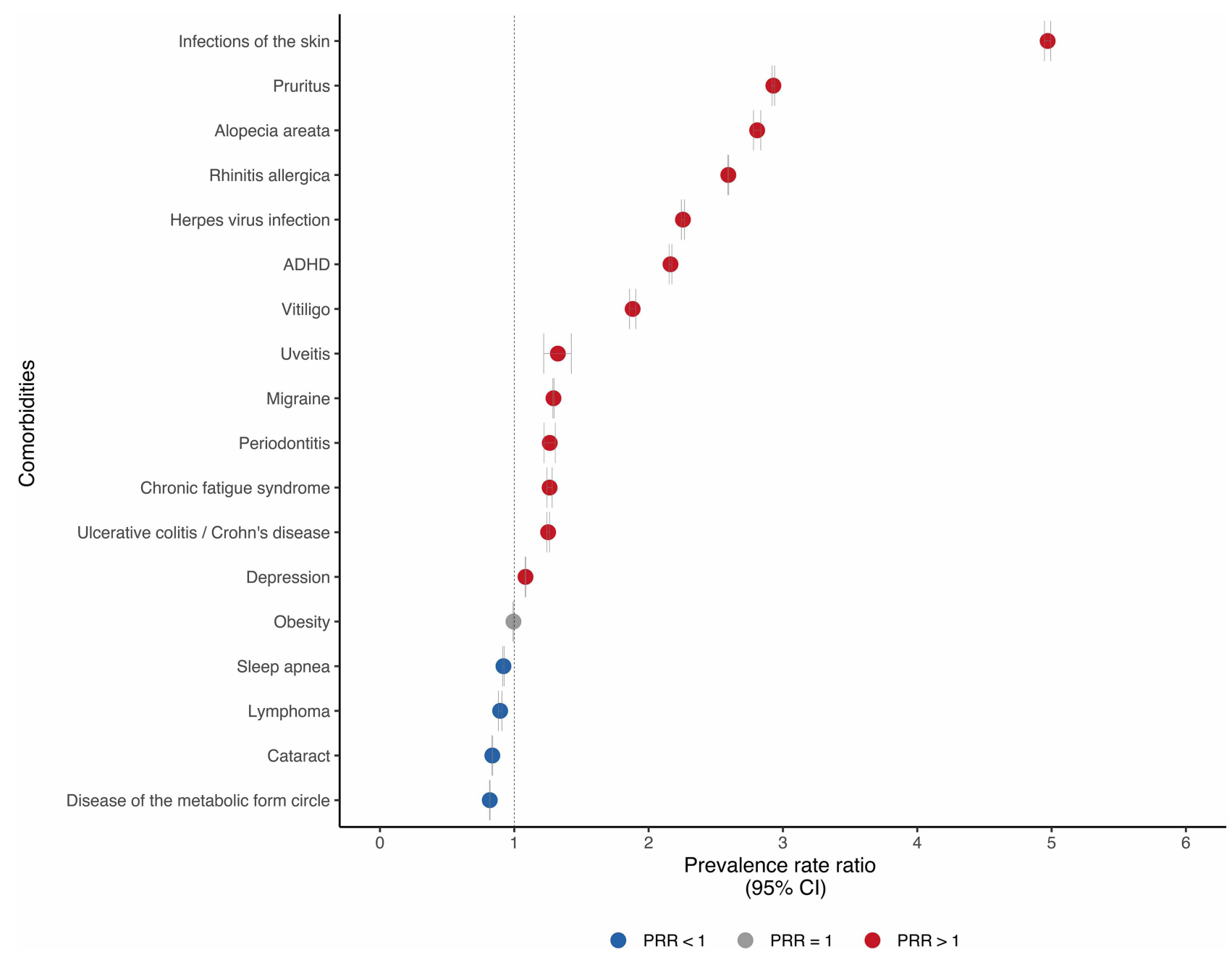

Figure I Most frequent comorbidities in 2018 in relation: prevalence among insured people with atopic dermatitis/prevalence among insured people without atopic dermatitis.

Abbreviation: ADHD, attention deficit hyperactivity disorder.

$74.20 \%$ ). About $23.48 \%$ received antihistamines with a total of 514,423 prescriptions. Systemic glucocorticosteroids preparations were used most frequently by $24.99 \%$ of the insured persons. Biologic therapy using a monoclonal antibody, dupilumab, was used in $0.64 \%$ of patients (Table 4 ).

\section{Prescribers}

Almost $40 \%$ of the relevant drugs were prescribed by a dermatologist, followed by GPs with $36.74 \%$. Pediatricians and doctors of internal medicine take a lower prescription share in the care of patients with $\mathrm{AD}$ with $23.10 \%$ and $15.62 \%$, respectively.

Of the anti-inflammatory drugs, systemic glucocorticosteroids preparations are used most frequently and are most often prescribed by a GP (35.67\%). The system-therapeutic agent methotrexate is most often prescribed by an internist (58.47\%). In comparison, ciclosporin is prescribed by a dermatologist much more frequently, at $44.00 \%$. The biological agent dupilumab, which was approved by the US Food and Drug Administration (FDA) and the European Medicines Agency (EMA) in 2017, has so far been prescribed primarily, at $66.67 \%$ by dermatologists (Figure 2).

Tacrolimus was comparatively rarely prescribed. The share of this prescription of tacrolimus and pimecrolimus by pediatricians is comparatively low in comparison to dermatologists, who mainly use urea and topical antibiotics. Within the topical corticosteroid classes, class I and class II drugs will be prescribed more frequently by GPs and pediatricians than by dermatologists (Figure 2). 
Table 4 Prescriptions of Relevant Drugs in Atopic Dermatitis Care (Insured Persons with AD in 2019; N = 3,074,095)

\begin{tabular}{|c|c|c|c|c|c|}
\hline \multicolumn{2}{|l|}{ Drug Substance } & \multirow{2}{*}{$\begin{array}{r}\mathbf{n} \\
1,278,832\end{array}$} & \multirow{2}{*}{$\begin{array}{r}\% \\
41.60\end{array}$} & \multirow{2}{*}{$\begin{array}{r}\text { mo } \\
2,421,505\end{array}$} & \multirow{2}{*}{$\begin{array}{r}\text { DDD } \\
82,888,415\end{array}$} \\
\hline Total topical & & & & & \\
\hline & Glucocorticosteroids* & $1,132,908$ & 88.59 & $\mathrm{I}, 962,6 \mathrm{II}$ & $75,007,526$ \\
\hline & Class I & 58,933 & 4.60 & 74,125 & $\mathrm{I}, 808,408$ \\
\hline & Class II & 148,178 & 11.59 & 198,530 & $4,494,494$ \\
\hline & Class III & 842,555 & 65.88 & $1,328,779$ & $60,003,876$ \\
\hline & Class IV & 83,885 & 6.56 & 126,024 & $4,404,052$ \\
\hline & Combinations with antiseptics & $|14,5| 7$ & 8.59 & $|46| \mid 4$, & $2,145,606$ \\
\hline & Combinations with antibiotics & 27,340 & 2.13 & 35,132 & 646,916 \\
\hline & Other combinations & 37,431 & 2.93 & 53,907 & $\mathrm{I}, 504,174$ \\
\hline & Tacrolimus & 80,715 & 6.31 & III,408 & $2,008,820$ \\
\hline & Pimecrolimus & 123,567 & 9.66 & $17 \mid, 022$ & $3,099,646$ \\
\hline & Urea & 13,634 & 1.07 & 20,543 & $1,346,989$ \\
\hline & Antibiotics & 128,593 & 10.06 & 152,964 & $\mathrm{I}, 063,297$ \\
\hline & Tars & 2,151 & 0.17 & 2,957 & 362,137 \\
\hline Total systemic & & $1,263,857$ & 41.11 & $2,803,926$ & $63,023,747$ \\
\hline \multirow[t]{2}{*}{ Non-anti-inflammatory } & Antibiotics & 937,824 & 74.20 & $1,602,249$ & $13,732,287$ \\
\hline & Antihistamines & 296,855 & 23.48 & 514,423 & $20,890,776$ \\
\hline Anti-inflammatory, biologics & Dupilumab & 8,151 & 0.64 & 30,801 & $2,116,818$ \\
\hline \multirow[t]{6}{*}{ Anti-inflammatory, non-biologicals } & Glucocorticosteroids & 315,835 & 24.99 & 549,323 & $21,291,204$ \\
\hline & Methotrexat & 14,123 & 1.12 & 42,841 & $2,928,436$ \\
\hline & Azathioprine & 4,639 & 0.37 & 25,696 & 966,059 \\
\hline & Ciclosporin & 3,370 & 0.27 & 19,628 & 402,420 \\
\hline & Alitretinoin & 2,258 & 0.18 & 10,263 & 380,638 \\
\hline & Mycophenolic acid & $|, 49|$ & 0.12 & 8,701 & 315,109 \\
\hline
\end{tabular}

Notes: $*$ The classes of topical glucocorticosteroids based on the national classification: ${ }^{22}$ Class I = weakly effective, Class II = moderately effective, Class III = strongly effective and Class IV = very strongly effective. In practical use, the potency is not necessarily associated with more frequent adverse effects.

Abbreviations: $n$, number of patients; mo, medication order; DDD, defined daily dose.

\section{Discussion}

With a total prevalence of $4.21 \%$ in 2019 , about 3.6 million persons in Germany had AD. The annual prevalence among adults over 20 years of age was $3.31 \%$. Another prevalence study using health insurance data of adults found marginally higher prevalence rates. ${ }^{14}$ Possibly, differences may be attributed to minimum age of the samples ( $\geq 20$ years vs $\geq 18$ years). Analyses based on survey data showed lower prevalence of $1.45 \%$ among employed people in $2017^{17}$ and $2.2 \%$ in $2011 .{ }^{12}$ In these studies, it could also be shown that women suffered from AD more frequently than men. These databases are only comparable to a limited extent since there are insured members in the SHI population that may not be employed.

The highest prevalence of $9.24 \%$ was seen in children under 15 years. The German Health Interview and Examination Survey for Children and Adolescents
(KiGGS study) indicates a comparable overall prevalence of $7.0 \%$ in children and adolescents under 17 years. ${ }^{16}$ Another study with health insurance data with almost 300,000 insured children showed a prevalence of $10.4 \%$ in $2009 .{ }^{13}$ The authors also reported a high prevalence of $17.1 \%$ at a young age ( 0 to 2 years) and a marked decrease to $7.3 \%$ at the age of 14 to 18 years. ${ }^{13}$ Comparable distributions in childhood were also found in Korea. Here, the highest prevalence was found in preschool $(11.3 \%)$ and school-age children (14.6\%). ${ }^{18}$

Patients with $\mathrm{AD}$ have an increasing risk of skin infections, pruritus, alopecia areata and rhinitis allergica ${ }^{14,26-29}$ which has also been shown in other studies. According to the recommendations of the German S2k guideline on diagnosis and treatment of $\mathrm{AD}$, allergic rhinitis should be considered as a contributing factor. Furthermore, the guideline refers to the association of $\mathrm{AD}$ with mental illness. $^{30}$ 


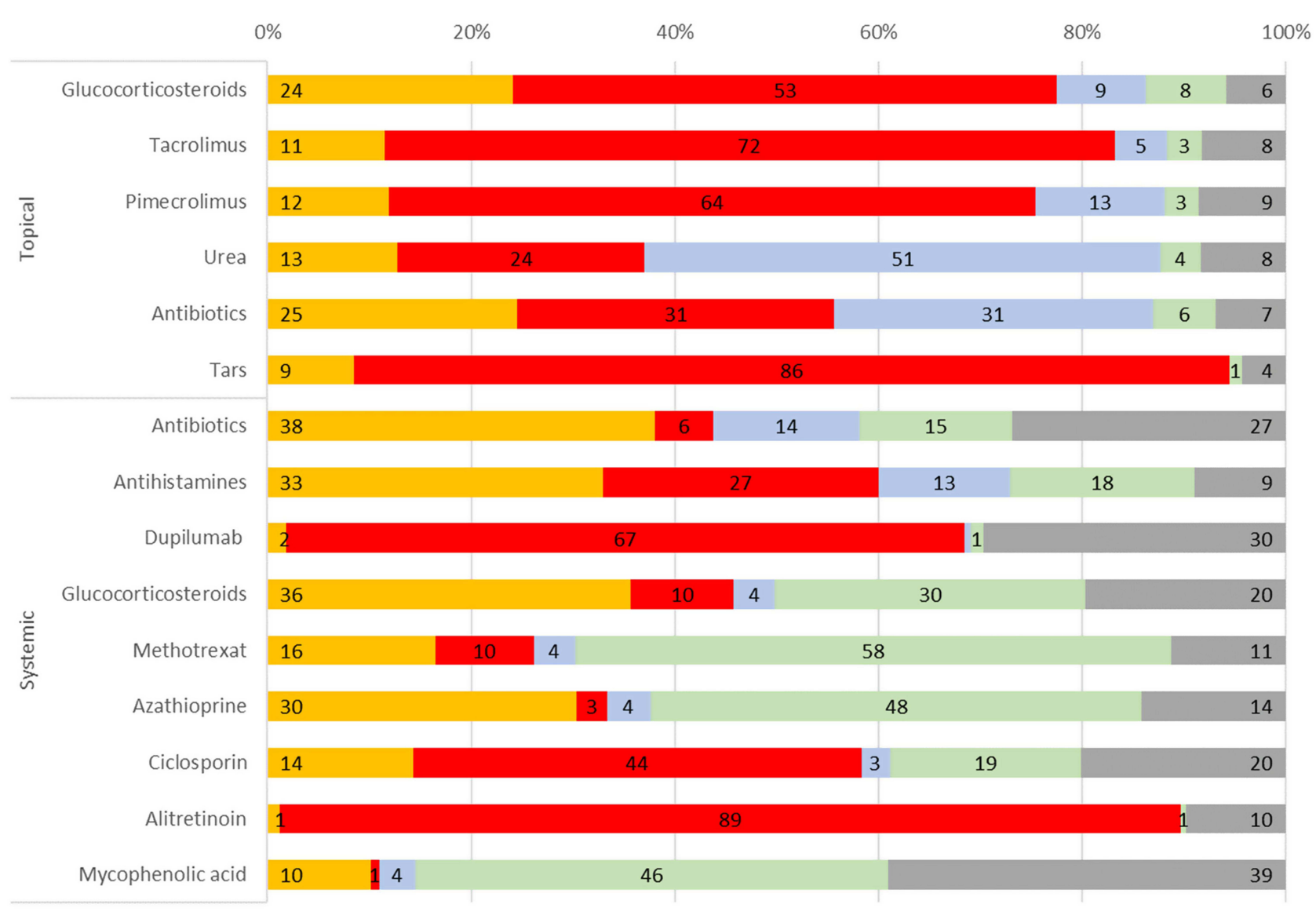

$\square$ General practitioner $\mathbf{\square}$ Dermatologist $\square$ Paediatrician $\square$ Internist $\square$ Other

Figure 2 Prescriptions of relevant drugs (DDD in \%) in atopic dermatitis care by medical specialist designation.

Tracing back prescriptions predominantly to glucocorticoid steroids and calcineurin inhibitors, the analyses of topical therapies indicated a guideline-appropriate supply in the majority of cases. ${ }^{30,32}$ Most frequently, the patients received ointments containing topical glucocorticosteroids, especially class III. The authors of a cross-sectional study on healthcare science came to a similar conclusion. ${ }^{19}$ At the same time, therapies which are useful according to guidelines and clinical studies, especially the tacrolimus or pimecrolimus ointment, which only $6.31 \%$ and $9.66 \%$ of the insured receive, are not sufficiently used. ${ }^{33,34}$ In contrast, the proportion of tacrolimus by pediatricians is comparatively low. However, urea and topical antibiotics are most frequently used by pediatricians. Their indication must be critically reviewed in further analyses, as they do not represent a standard in care. Within the prescribed topical corticosteroid classes, it is positive that preparations of drug class III are used most frequently, which also corresponds to the guidelines.
Again, it should be questioned that preparations of the corticosteroid classes I and II are more often prescribed by GPs and paediatricians than by dermatologists. In children and adolescents, as well as in adults in general, it is better to use class III or class IV topical treatments while maintaining the maximum duration of use rather than class I continuous administration. Clinical studies show that the use of moderate to potent topical glucocorticosteroids can lead to shorter treatment times, indicating greater success and possibly fewer side effects, resulting in greater success with fewer side effects. ${ }^{31,32}$

Of the anti-inflammatory drugs, systemic glucocorticosteroid preparations are used most frequently and are most often prescribed by a GP. Since systemic glucocorticosteroids should only be used in acute attacks and were associated with a lower quality of life and lower satisfaction parameters, ${ }^{19}$ their use should be reconsidered. Other systemic therapeutic agents (ciclosporin, azathioprine, methotrexate, mycophenolic acid), which are usually 
associated with more severe side effects, were prescribed to a small proportion of the insured persons $(1.9 \%)$. Methotrexate, which is classified as a third-line treatment option for moderate to severe $\mathrm{AD}$, is most often prescribed by a GP. Although these are not approved for permanent use, the average number of daily doses (defined daily dose per insured person) showed that methotrexate or azathioprine are used as permanent therapy. It should be noted that systemic therapeutics such as methotrexate are also approved to treat other conditions; the database does not contain reasons for each prescription. Ciclosporin as firstline treatment option ${ }^{35,36}$ is prescribed significantly more frequently by a dermatologist in the present analysis.

The new treatment option dupilumab is the first approved biological agent (April 2017) for the treatment of adult and adolescent patients with moderate to severe $\mathrm{AD}$, whose disease is not adequately controlled by topical prescription therapies or when such therapies are not advisable. ${ }^{37,38}$ With a relatively low share of $0.64 \%$, insured people were treated with dupilumab, which has so far been primarily prescribed by dermatologists. Although it is not possible to estimate the proportion of people for whom the therapy is advisable, the low percentage is still worth increasing. In comparison, the majority of patients with severe $\mathrm{AD}$ in the Treatment of Atopic eczema (TREAT) Registry are treated with dupilumab or ciclosporin. ${ }^{26,39}$ It should be noted that the registry contains only patients with moderate to severe AD treated in dermatological clinics or by dermatological GPs and thus in a specialized setting.

\section{Strengths and Limitations of the Work}

Epidemiological and scientific data are needed to improve healthcare planning and a more targeted use of existing resources of the German healthcare system. SHI data can be used to analyze or describe morbidity estimates, utilization of health services, care patterns, quality of healthcare, resource consumption and costs. ${ }^{24,40}$ The data are based on a large population, are cross-sectoral (eg, outpatient and inpatient care, prescribed treatments) and insured people can be viewed over a long period. Another advantage of routine SHI data is the absence of recall or selection bias. Furthermore, a number of limitations has to be considered. The reliability of the estimated prevalence and the care situation may be limited by a) the encryption of the diagnoses b) underserved morbidity c) over-the-counter (OTC) drugs or d) the considered population. The proportion of people with $\mathrm{AD}$ could be higher and limits the reliability of the statements. ${ }^{40}$ (a) For example, due to insufficient or missing differential diagnosis (misdiagnosis, eg, psoriasis or eczema) or due to the coding behavior of the practitioner. (b) The influence of under-reporting due to untreated morbidity is estimated to be relatively low as $\mathrm{AD}$ is considered a severe disease that significantly restricts the patient's quality of life. Thus, patients are likely to make use of healthcare services. (c) A large proportion of patients with $\mathrm{AD}$ were treated with topical drugs. Many topical drugs used in the treatment of $\mathrm{AD}$ are available without prescription. From other primary studies, many patients reported treating their $\mathrm{AD}$ with OTC drugs. ${ }^{1}$ Unfortunately, it is not possible to determine or estimate how often this occurs within the present SHI data. We presented data on people insured through a public system and therefore cannot make statements about those insured with private healthcare $(10 \%$ of the German population ${ }^{20}$ ). Furthermore, the analysis conducted here is based on data of only one health insurance company. The prevalence estimate may not be generalizable to the entire SHI system, or the German population. Even the standardization of data according to age and sex cannot fully eliminate this assumption. ${ }^{41}$ For internal consistency checks, a comparison of administrative morbidity rates from different data sources should be sought.

\section{Conclusion}

The present results show that $\mathrm{AD}$ is a common skin disease affecting mainly children. Patients with AD often suffer from comorbidities that should be considered when choosing treatment. In addition, our results show that only one-third of patients are treated by a specialist and in some cases there is still a significant underuse, especially with regard to innovative drugs. Interdisciplinary care provided by specialists such as dermatologists could address the underuse as well as establishing innovative drugs as an option in standard $\mathrm{AD}$ care. Furthermore, a reduction of systemic glucocorticosteroids, which are mainly prescribed by GPs, should be aimed at against the background that alternatives already conforming to the guidelines are available.

Children, who suffer most frequently from $\mathrm{AD}$, are particularly limited in their quality of life. A guidelinebased therapy, therefore, plays a particularly important role for these patients. Innovative drugs will also be approved more frequently for this age group in the future. Furthermore, the limited number of studies on this vulnerable patient group therefore be given more scientific attention in the future. Further research projects should aim to 
describe the healthcare of children to identify undersupply and to derive recommendations for action.

\section{Abbreviations}

$\mathrm{AD}$, atopic dermatitis; SHI, statutory health insurance; TK, Techniker Krankenkasse; ICD-10-GM, International Classification of Diseases codes German modification; ATC, Anatomical Therapeutic Chemical; CI, 95\% confidence intervals; RR, rate ratios; FDA, Food and Drug Administration; EMA, European Medicines Agency; GP, general practitioner; OTC, over-the-counter.

\section{Data Sharing Statement}

The data of the statutory health insurance (SHI) are primarily documented for billing purposes. According to $\S$ 287 of the German Social Code, Book V, the statutory health insurance funds are allowed to evaluate their data files under certain conditions for scientific research projects according to $\S 303$ a (data transparency).

\section{Acknowledgments}

We thank the Techniker Krankenkasse (TK) for collaboration and allocation of data and the Scientific Communication Team of the IVDP, in particular Mathilda Meyer and Mario Gehoff, for copy editing.

\section{Disclosure}

Dr Kristina Hagenström report grants from Universitätsklinikum Hamburg-Eppendorf (UKE), during the conduct of the study; Dr Nicole Mohr report grants from Techniker Krankenkasse, Hamburg, during the conduct of the study; Dr Jana Petersen report grants from Techniker Krankenkasse, during the conduct of the study; Ms Claudia Garbe report grants from Techniker Krankenkasse, during the conduct of the study; Prof Matthias Augustin has served as consultant and/or paid speaker for and/or has received research grants and/or honoraries for consulting and/or scientific lectures and/or participated in clinical trials sponsored by companies that manufacture drugs used for the treatment of atopic dermatitis including AbbVie, Almirall, Beiersdorf, Galderma, LEO and Sanofi. The authors report no other conflicts of interest in this work.

\section{References}

1. Langenbruch A, Radtke M, Franzke N, Ring J, Foelster-Holst R, Augustin M. Quality of health care of atopic eczema in Germany: results of the National Health Care Study AtopicHealth. J Eur Acad Dermatol Venereol. 2014;28(6):719-726. doi:10.1111/jdv.12154
2. Misery L, Finlay AY, Martin N, et al. Atopic dermatitis: impact on the quality of life of patients and their partners. Dermatology. 2007;215(2):123-129. doi:10.1159/000104263

3. Gutknecht M, Reinert R, Augustin M. Review of health economic analyses in atopic dermatitis: how diverse is the literature? Expert Rev Pharmacoecon Outcomes Res. 2019;19(2):127-145. doi:10.1080/14737167.2019.1549491

4. Nørreslet LB, Ebbehøj NE, Ellekilde Bonde JP, Thomsen SF, Agner T. The impact of atopic dermatitis on work life a systematic review. J Eur Acad Dermatol Venereol. 2018;32 (1):23-38. doi:10.1111/jdv.14523

5. Bieber T. Atopic dermatitis. N Engl J Med. 2008;358:1483-1494. doi:10.1056/NEJMra074081

6. Silverberg JI. Public health burden and epidemiology of atopic dermatitis. Dermatol Clin. 2017;35(3):283-289. doi:10.1016/j. det.2017.02.002

7. Carroll CL, Balkrishnan S, Feldman SR, Fleischer AB, Manuel JC. The burden of atopic dermatitis: impact on the patient, family, and society. Pediatr Dermatol. 2005;22:192-199. doi:10.1111/j.15251470.2005.22303.x

8. Lewis V, Finlay A. 10 years experience of the Dermatology Life Quality Index (DLQI). J Investig Dermatol Symp Proc. 2004;9::169 -169. doi:10.1111/j.1087-0024.2004.09113.x

9. Schäfer I, Rustenbach SJ, Zimmer L, Augustin M. Prevalence of skin diseases in a cohort of 48,665 employees in Germany. Dermatology. 2008;217:169-172. doi:10.1159/000136656

10. Schmitt J. Behandlungsziele und Zufriedenheit mit der medizinischen Versorgung von Erwachsenen mit Neurodermitis. In: Kirch W, Badura B, Pfaff H, editors. Prävention Und Versorgungsforschung. Berlin: Springer; 2008:819-832.

11. Augustin M, Herberger K, Hintzen S, Heigel H, Franzke N, Schäfer I. Prevalence of skin lesions and need for treatment in a cohort of 90 880 workers. Br J Dermatol. 2011;165(4):865-873. doi:10.1111/ j.1365-2133.2011.10436.x

12. Langen U, Schmitz R, Steppuhn H. Prevalence of allergic diseases in Germany: results of the German Health Interview and Examination Survey for Adults (DEGS1). Bundesgesundheitsblatt Gesundheitsforschung Gesundheitsschutz. 2013;56(5-6):698-706.

13. Augustin M, Radtke MA, Glaeske G, et al. Epidemiology and comorbidity in children with psoriasis and atopic eczema. Dermatology. 2015;231:35-31. doi:10.1159/000381913

14. Radtke MA, Schäfer I, Glaeske G, Jacobi A, Augustin M. Prevalence and comorbidities in adults with psoriasis compared to atopic eczema. J Eur Acad Dermatol Venereol. 2017;31(1):151-157. doi:10.1111/jdv.13813

15. Barbarot S, Auziere S, Gadkari A, et al. Epidemiology of atopic dermatitis in adults: results from an international survey. Allergy. 2018;73(6):1284-1293. doi:10.1111/all.13401

16. Thamm R, Poethko-Müller C, Hüther A, Thamm M. Allergische Erkrankungen bei Kindern und Jugendlichen in Deutschland - querschnittergebnisse aus KiGGS Welle 2 und Trends. J Health Monit. 2018;3(3):3-18.

17. Zander N, Augustin M, Reinert R, Schäfer I. Atopic dermatitis shows significant cutaneous comorbidity: results from large-scale investigations in the working population. J Eur Acad Dermatol Venereol. 2020;34(1):135-141. doi:10.1111/jdv.15792

18. Ha J, Lee SW, Yon DK. Ten-Year trends and prevalence of asthma, allergic rhinitis, and atopic dermatitis among the Korean population, 2008-2017. Clin Exp Pediatr. 2020;63(7):278-283. doi:10.3345/ cep. 2019.01291

19. Steinke S, Langenbruch A, Ständer S, Franzke N, Augustin M. Therapeutic benefits in atopic dermatitis care from the patients' perspective. Results of the German National Health Care Study 'Atopic Health'. Dermatology. 2014;1(4):358-364. 
20. Statutory health insurance [homepage on the Internet]. Bonn: GKV-Spitzenverband; 2019. Available from: https://www.gkvspitzenverband.de/english/statutory_health_insurance/statutory_ health_insurance.jsp. Accessed May 3, 2020.

21. Busse R, Blumel M. Germany: health system review. Health Syst Transit. 2014;16(2):1-296.

22. Niedner R. Glukokortikosteroide in der Dermatologie: kontrollierter Einsatz erforderlich. Dt Ärztebl. 1996;93:A-2868-72.

23. Hoffmann W, Latza U, Baumeister SE, et al. Guidelines and recommendations for ensuring Good Epidemiological Practice (GEP): a guideline developed by the German Society for Epidemiology. Eur J Epidemiol. 2019;34(3):301-317. doi:10.1007/s10654-019-00500-x

24. Swart E, Ihle P, Gothe H, Matusiewicz D. editors. Routinedaten im Gesundheitswesen - Handbuch Sekundärdatenanalyse: Grundlagen, Methoden und Perspektiven. 2nd ed. Bern: Verlag Hans Huber; 2014.

25. KM 6-Statistik (gesetzliche Krankenversicherung: Versicherte). [homepage on the Internet]. Ort: gesundheitsberichterstattung des Bundes (BGE-Bund); 2020. Available from: http:/www.gbe-bund.de/gbe10/tre cherche.prc_them_rech?tk $=2700 \& \mathrm{tk} 2=2730 \&$ p_uid $=$ gast $\&$ p_aid $=$ 0\&p_sprache=D\&cnt_ut=0\&ut=2730. Accessed September 4, 2020.

26. Heratizadeh A, Haufe E, Stölzl D, et al. Baseline characteristics, disease severity and treatment history of patients with atopic dermatitis included in the German AD Registry TREATgermany. $J$ Eur Acad Dermatol Venereol. 2020;34(6):1263-1272. doi:10.1111/ jdv. 16078

27. Alexander H, Paller AS, Traidl-Hoffmann C, et al. The role of bacterial skin infections in atopic dermatitis: expert statement and review from the International Eczema Council Skin Infection Group. Br J Dermatol. 2020;182(6):1331-1342. doi:10.1111/bjd.18643

28. Darsow U, Pfab F, Valet M, et al. Pruritus and atopic dermatitis. Clin Rev Allergy Immunol. 2011;41(3):237-244. doi:10.1007/s12016-0108230-2

29. Mohan GC, Silverberg JI. Association of vitiligo and alopecia areata with atopic dermatitis: a systematic review and meta-analysis. JAMA Dermatol. 2015;151(5):522-528. doi:10.1001/jamadermatol.2014.3324

30. Werfel T, Heratizadeh A, Aberer W, et al. S2k guideline on diagnosis and treatment of atopic dermatitis - short version. J Dtsch Dermatol Ges. 2016;14(1):92-106. doi:10.1111/ddg.12871

31. Wollenberg A, Barbarot S, Bieber T, et al. Consensus-based European guidelines for treatment of atopic eczema (atopic dermatitis) in adults and children: part I. J Eur Acad Dermatol Venereol. 2018;32(5):657-682. doi:10.1111/jdv.14891

32. Wollenberg A, Barbarot S, Bieber T, et al. Consensus-based European guidelines for treatment of atopic eczema (atopic dermatitis) in adults and children: part II. J Eur Acad Dermatol Venereol. 2018;32(6):850-878.
33. Garside R, Stein K. Castelnuovo et al. The effectiveness and cost-effectiveness of pimecrolimus and tacrolimus for atopic eczema: a systematic review and economic evaluation. Health Technol Assess. 2005;9(29):1-230. doi:10.3310/hta9290

34. Fröschl B, Arts D, Leopold C. Topische antientzündliche Behandlung der Neurodermitis im Kindesalter. GMS Health Technol Assess. 2007;3:Doc09.

35. Roekevisch E, Spuls PI, Kuester D, Limpens J, Schmitt J. Efficacy and safety of systemic treatments for moderate-to-severe atopic dermatitis: a systematic review. J Allergy Clin Immunol. 2014;133 (2):429-438. doi:10.1016/j.jaci.2013.07.049

36. Schmitt J, Schaekel K, Foelster-Holst R, et al. Prednisolone vs. ciclosporin for severe adult eczema - an investigator-initiated double-blind placebo-controlled multicentre trial. $\mathrm{Br} J$ Dermatol. 2010;162(3):661-668. doi:10.1111/j.1365-2133.2009.09561.x

37. Seegräber M, Srour J, Walter A, Knop M, Wollenberg A. Dupilumab for treatment of atopic dermatitis. Expert Rev Clin Pharmacol. 2018;11(5):467-474. doi:10.1080/17512433.2018.1449642

38. Werfel T, Heratizadeh A, Aberer W et al. Aktualisierung „Systemtherapie bei Neurodermitis“ zur Leitlinie Neurodermitis [atopisches Ekzem; atopische Dermatitis] Entwicklungsstufe: s2k; 2020. Available from: https://www.awmf.org/fileadmin/user_upload/ Leitlinien/013_D_Dermatologische_Ges/013-0271_S2k_ Neurodermitis_Aktualisierung-Systemtherapie_2020-06.pdf.

Accessed September 4, 2020.

39. Schmitt J, Abraham S, Trautmann F, et al. Usage and effectiveness of systemic treatments in adults with severe atopic eczema: first results of the German Atopic Eczema Registry TREATgermany. J Dtsch Dermatol Ges. 2017;15(1):49-59.

40. Schubert I, Ihle P, Köster I. Verwendung von GKV-Diagnosen in der Sekundärdatenfoschung. In: Swart E, Ihle P, editors. Routinedaten Im Gesundheitswesen - Handbuch Sekundärdatenanalyse: Grundlagen, Methoden Und Perspektiven. Bern: Verlag Hans Huber; 2005:235-242.

41. Hoffmann F, Icks A. Structural differences between health insurance funds and their impact on health services research: results from the Bertelsmann Health-Care Monitor. Gesundheitswesen. 2012;74 (5):291-297.
Clinical Epidemiology

\section{Publish your work in this journal}

Clinical Epidemiology is an international, peer-reviewed, open access, online journal focusing on disease and drug epidemiology, identification of risk factors and screening procedures to develop optimal preventative initiatives and programs. Specific topics include: diagnosis, prognosis, treatment, screening, prevention, risk factor modification,

Submit your manuscript here: https://www.dovepress.com/clinical-epidemiology-journal systematic reviews, risk \& safety of medical interventions, epidemiology \& biostatistical methods, and evaluation of guidelines, translational medicine, health policies \& economic evaluations. The manuscript management system is completely online and includes a very quick and fair peer-review system, which is all easy to use. 